\title{
Role of Serum Procalcitonin Level in Differentiating between Pulmonary Tuberculosis and Community-Acquired Pneumonia
}

\author{
Mohammad Shameem ${ }^{*}$, Mazhar Alam¹, Shagufta Moin², Rakesh Bhargava ${ }^{1}$, \\ Zuber Ahmad', Jamal Akhtar' \\ ${ }^{1}$ Department of Tuberculosis and Respiratory Diseases, Jawaharlal Nehru Medical College, Aligarh Muslim \\ University, Aligarh, UP 202002, India \\ ${ }^{2}$ Department of Biochemistry, Jawaharlal Nehru Medical College, Aligarh Muslim University, Aligarh, India \\ Email: ${ }^{*}$ drshameem123@gmail.com
}

Received 20 May 2014; revised 19 June 2014; accepted 18 July 2014

Copyright @ 2014 by authors and Scientific Research Publishing Inc.

This work is licensed under the Creative Commons Attribution International License (CC BY). http://creativecommons.org/licenses/by/4.0/

(c) (i) Open Access

\begin{abstract}
Pulmonary Tuberculosis (PTB) and Community-Acquired Pneumonia (CAP) are common causes of consolidation patch in chest radiograph. Sputum Z-N staining is positive in $30 \%$ to $60 \%$ cases only and sputum examination has poor yield in CAP. This study aimed to assess the value of serum Procalcitonin (PCT) levels in patients with Pulmonary Tuberculosis (PTB) and Community-Acquired Pneumonia (CAP). Patients with new opacity in chest radiograph were included in the study. Serum sample were taken at admission and stored. Patient's diagnosis were confirmed and categorized into pulmonary TB group (32) and community-acquired pneumonia group (23). Their mean PCT level was compared with mean PCT level of 25 controls. Serum procalcitonin levels were found to be significantly elevated in patients of community-acquired pneumonia as compared to patients of pulmonary tuberculosis. In presence of consolidation in x-ray chest, increased level of serum procalcitonin might be used to differentiate pulmonary tuberculosis from community-acquired pneumonia. High level of serum procalcitonin was associated with high mortality rate in community-acquired pneumonia patients.
\end{abstract}

\section{Keywords}

Procalcitonin, Tuberculosis, Community-Acquired Pneumonia

\footnotetext{
${ }^{*}$ Corresponding author.
} 


\section{Introduction}

There are large number of patients presenting to pulmonary medicine OPD with fever, cough and consolidation in $\mathrm{x}$-ray chest. Sometimes, clinical symptoms are minimal but there is extensive consolidation in chest $\mathrm{x}$-ray. Diagnosis of such patient may vary from community-acquired pneumonia, pulmonary tuberculosis to Interstitial Lung Diseases. In pulmonary diseases, yield of microbiological investigation is low and radiological findings are quite overlapping. Sometimes, this creates problem in deciding whether the problem is infective or non-infective leading to injudicious prescriptions of antibiotics or delayed treatments. This needs invasive methods of investigations, which are associated with increased incidence of complications. Pulmonary tuberculosis and pneumonia are the most common infective disease requiring admission in pulmonary medicine ward. There are 9 million new cases of pulmonary tuberculosis worldwide every year and 30\% to 60\% of them are smear negative tuberculosis. This leads to delay in treatment and extra investigation to rule out other diagnoses. Sputum Z-N staining is the first and most rapid investigation for diagnosis of pulmonary tuberculosis. But it is positive in only $50 \%$ to $70 \%$ of active pulmonary tuberculosis. Yield of sputum Z-N staining is especially low in, children, elderly, diabetes mellitus, HIV and other immune-compromised patients. Primary progressive pulmonary tuberculosis also has lower sputum positivity rate. Sputum culture for mycobacterium is time-taking and costly and not easily available, bronchial-lavage is an invasive method and it requires expertise. Often elderly patients of pneumonia presents with low grade fever and a small amount of sputum production and poor responses to antibiotics. 10\% of CAP patients develop non-responding CAP (NCAP) [1] leading to difficulties in differentiating pneumonia from tuberculosis. With this concern, there is a need of alternate diagnostic test.

\section{Patients and Study Design}

This was planned as prospective study. This study was undertaken in the Department of Tuberculosis And Respiratory Diseases and Department of Biochemistry, Jawaharlal Nehru Medical College, Aligarh Muslim University, Aligarh during the period 2011-2013. The subjects were selected from the patients attending OPD or admitted in IPD of Tuberculosis and Respiratory Diseases. The patients of pulmonary tuberculosis were diagnosed on the basis of sputum Z-N staining, Sputum culture for Mycobacterium Tuberculosis and Chest x-ray. Patients of community-acquired pneumonia were diagnosed on the basis of History, Examination and Investigations e.g. fever, cough, consolidation in chest x-ray, sputum gram staining, sputum culture, blood culture and resolution of consolidation after recommended course of antibiotics (As per American Thoracic Society Guideline).

All the patients of pulmonary tuberculosis and CAP were further evaluated for sepsis and organ dysfunction and classified into with sepsis or without sepsis as per Sepsis Survival Campaign Guidelines 2012. Patients of CAP were assessed for severity by using CURB-65 Scoring and Pneumonia Severity Index and severity score was assigned. Complications and mortality were recorded.

\section{Investigations Done for Diagnosis and Severity Assessment}

Investigations done for confirmation of diagnosis and assessing severity were chest X-ray, Haemogram, Renal function test, Liver function test, Blood sugar, Serum electrolyte, Arterial Blood Gas Analysis, Sputum Z-N Staining, Sputum culture for Mycobacterium Tuberculosis, Sputum culture for pyogenic bacteria, Blood culture, ELISA for HIV

\subsection{Selection of Subjects}

The protocol used for the study was in accordance with guidelines of institutional ethical committee. Seventy patients were included in this study. Patients attending OPD or admitted in the IPD of Tuberculosis and Respiratory Diseases JNMCH during 2011 to 2013, with consolidation or cavity in chest X-ray were enrolled. Blood samples were taken before starting antibiotics or anti-tuberculosis treatment. Finally, 55 samples (32 pulmonary TB and 23 CAP) were tested for procalcitonin level. 15 Samples were discarded either because of hemolysis or patient had not taken treatment as advised. 25 samples were taken as control for comparison from age and sex matched healthy volunteers. The subjects were divided in the following groups.

- PTB: Pulmonary Tuberculosis Group (32 patients);

- CAP: Community-Acquired Pneumonia Group (23 patients); 
- Control: Apparently healthy age and sex matched volunteers.

\subsection{Exclusion Criteria}

- Patients with any infection other than pulmonary tuberculosis and CAP;

- CAP along with Carcinoma of lung.

\subsection{Collection of Blood and Isolation of Serum}

Blood samples were taken after informed written consent from all the study group subjects on first day before starting treatment with a disposable syringe \& needle, under all aseptic conditions. Serum was separated by centrifuging the blood at $300 \mathrm{rpm}$ for 20 minutes. Samples were stored in aliquots at $-20^{\circ} \mathrm{C}$ until assayed.

\subsection{Estimation of Serum Procalcitonin}

It was based on the principle of ELISA. This assay employs an antibody specific for human procalcitonin coated on a 96-well plate. Standards and samples are pipetted into the wells and procalcitonin present in a sample is bound to the wells by the immobilized antibody. The wells are washed and biotinylated anti-human procalcitonin antibody added. After washing away unbound biotinylated antibody, HRP-conjugated streptavidin is pipetted to the wells. The wells are again washed, a TMB substrate solution is added to the wells and color develops in proportion to the amount of procalcitonin bound. The Stop solution changes the color from blue to yellow, and the intensity of the color is measured at $450 \mathrm{~nm}$.

\subsection{Assay Procedure}

$100 \mu \mathrm{l}$ standard or sample was added to each well. Well covered and incubated over night at $4^{\circ} \mathrm{C}$ with gentle shaking. The solution was discarded and washed 4 times with $1 \times$ wash solution. After the last wash, any remaining wash buffer was removed by decanting. The plate was inverted and blotted against clean blotting paper. $100 \mu \mathrm{L}$ of $1 \mathrm{x}$ prepared biotinylated antibody was added to each well and incubated for $1 \mathrm{hr}$ at room temperature with gentle shaking. The solution was discarded and the wash was repeated as described earlier. $100 \mu \mathrm{L}$ streptavudine solutions was added to each well, and incubated for 45 minute at room temperature with gentle shaking. $100 \mu \mathrm{L}$ of TMB One-Step substrate reagent was added to each well and incubated for 30 minute at room temperature in dark with gentle shaking. $50 \mu \mathrm{L}$ of stop solution was added to each well and read immediately.

\subsection{Calculation of Results}

We Calculated the Mean absorbance for each set standards, controls and samples, and subtract the average zero standard optical density. The Standard curve was plotted by using Sigma plot software, with standard concentration on $\mathrm{x}$ axis and absorbance on the $\mathrm{y}$-axis. The best-fit straight line was drawn through the standard points Standard level of procalcitonin was plotted at $450 \mathrm{~nm}$ (Figure 1).

\subsection{Sensitivity of the Kit}

The minimum detectable dose of procalcitonin is typically less than $30 \mathrm{pg} / \mathrm{ml}$.

\subsection{Statistical Analysis}

SPSS version 16 software package was used to analyze the data. The data is reported as mean \pm SD. The results were statistically analyzed using ANOVA and Students t-test. $\mathrm{P} \leq 0.05$ was considered as statistically significant.

\section{Observation and Results}

The present study was conducted on subjects attending OPD or IPD of Tuberculosis and Respiratory Diseases, Jawaharlal Nehru Medical College, AMU, Aligarh from 2011 to 2013. Analysis of Blood sample for serum procalcitonin was done in Department of Biochemistry, JNMCH, Aligarh. This study includes three groups of 


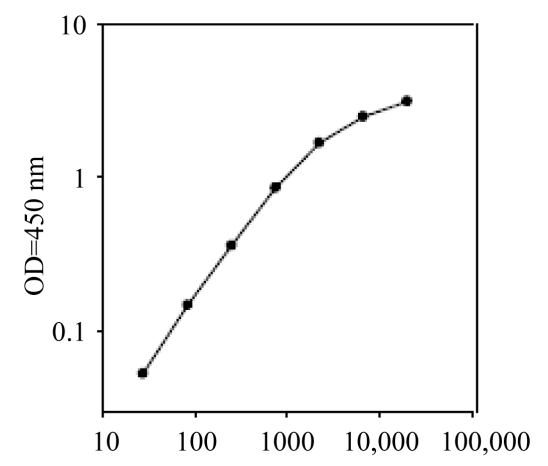

Figure 1. Standard procalcitonin concentration $(\mathrm{pg} / \mathrm{ml})$.

participants, Pulmonary Tuberculosis (PTB), Community-Acquired Pneumonia (CAP) and Controls. Each group is matched for age, sex and comorbidity. There are 32 patients (41\% Male, 59\% Female) in PTB group, mean age $48.59 \pm 17.92$ (Male $50.31 \pm 16.44$, Female $46.07 \pm 19.5$ ) years, 23 patients (35\% Male, $65 \%$ Female ) in CAP group, mean age $57.69 \pm 14.93$ (Male $57.26 \pm 15.26$, Female $58.37 \pm 15.26$ ) years and 25 (40\% Male, $60 \%$ Female) voluntary participants in control group, mean age $44.88 \pm 14.26$ (Male $44.46 \pm 15.14$, Female $45.5 \pm$ 14.45) years. In the pulmonary TB group, three were HIV positive, four had diabetes mellitus, three had systemic hypertension, 2 had COPD, and three had malnutrition and anemia. In the CAP group two were HIV positive. Four had diabetes mellitus, three had systemic hypertension, two had chronic kidney disease and four had COPD. On statistical analysis there was no significant difference in these conditions.

Of the 23 patients in the CAP group, four had a positive sputum culture for Streptococcus pneumoniae, one had positive blood culture for S. pneumoniae, and one had a positive sputum culture for Klebsiella pneumonie. The hospital mortality was 6.35 (2/32) in the PTB group and 21.7\% (5/23) in the CAP group.

\section{Data Analysis}

Data was analyzed using SPSS-16 software. ANOVA was used to analyze the difference in three study groups and independent t-test used to compare PCT levels in sepsis and non sepsis groups. Mean PCT levels in pulmonary tuberculosis, CAP and Controls were compared using ANOVA. On Analysis of Variance (ANOVA) testing, there was a significant difference in serum PCT levels at $\mathrm{P}<0.05$ for controls, pulmonary tuberculosis and CAP $[F(2,77)=33.962 ., P=0.000]$ (Table 1$)$.

Mean procalcitonin levels were $42.664 \mathrm{pg} / \mathrm{ml}$ in controls and $194.834 \mathrm{pg} / \mathrm{ml}$ in Pulmonary tuberculosis patients and $821.317 \mathrm{pg} / \mathrm{ml}$ in community-acquired pneumonia group (Figure 2). Mean PCT levels were also calculated in males and females in each group and they were compared for difference by using independent t-test. There was no significant difference in serum procalcitonin levels in males and females in any groups (Table 2, Figure 3).

Further, Post hoc comparisons using the Tukey HSD test indicate that the mean serum PCT for control group (Mean $=42.664, \mathrm{SD}= \pm 8.0205 \mathrm{pg} / \mathrm{ml}$ ) is not significantly different than those with pulmonary tuberculosis group (Mean $=194.834, \mathrm{SD}= \pm 145.2233 \mathrm{pg} / \mathrm{ml}$ ) with $\mathrm{P}$ value of 0.235 , Mean serum PCT for control group (M $=42.664, \mathrm{SD}= \pm 8.0205 \mathrm{pg} / \mathrm{ml})$ was significantly different than those in CAP group $(\mathrm{M}=821.317, \mathrm{SD}=$ $\pm 626.6993 \mathrm{pg} / \mathrm{ml}$ ) with $\mathrm{P}$ value of 0.000 and mean serum PCT level in pulmonary tuberculosis group (Mean = $194.834, \mathrm{SD}= \pm 145.2233 \mathrm{pg} / \mathrm{ml}$ ) is significantly different than those in CAP group (Mean $=821.317, \mathrm{SD}=$ $626.6993 \mathrm{pg} / \mathrm{ml}$ ) with P value of 0.000 . Taken together, these results suggest that PCT in CAP is significantly increased than those in pulmonary tuberculosis and controls. There is no significant difference in PCT level of pulmonary tuberculosis and controls. Patients in pulmonary tuberculosis and CAP group were further categorized into patient with sepsis and without sepsis and analysis of mean was done using independent t-test. In pulmonary tuberculosis group -8 patient were having sepsis and 25 were not having sepsis. Mean PCT level in pulmonary ТВ with sepsis group (377.912 $\pm 157.3 \mathrm{pg} / \mathrm{ml})$ was significantly higher than those in non sepsis group (123.202 $\pm 40.487 \mathrm{pg} / \mathrm{ml}$ ) with P value of 0.001 as shown in (Table 3, Figure 4).

In CAP group - 9 were in sepsis and 14 were not having sepsis. Mean PCT level in CAP with sepsis group $(1334.3 \pm 737.12)$ was significantly higher than those in non sepsis group (491.571 $\pm 176.19 \mathrm{pg} / \mathrm{ml})$ with $\mathrm{P}$ value 
Table 1. Procalcitonin levels (pg/ml) in different study groups.

\begin{tabular}{cccc}
\hline Groups & N & $\begin{array}{c}\text { Mean PCT Level } \\
(\mathrm{Pg} / \mathrm{ml})\end{array}$ & SD \\
\hline Control & 25 & 42.664 & \pm 8.0204 \\
Pulmonary & 32 & 194.834 & \pm 145.2233 \\
Tuberculosis & & 821.317 & \pm 626.699 \\
CAP & 23 & \\
\hline
\end{tabular}

Table 2. Mean PCT levels in males and females in different study groups.

\begin{tabular}{cccc}
\hline Groups & Male & Female & P value \\
\hline Pulmonary Tuberculosis & $192.984 \pm 167.131(\mathrm{n}=19)$ & $197.538 \pm 112.113(13)$ & 0.259 \\
CAP & $818.887 \pm 553.330(\mathrm{n}=15)$ & $825.875 \pm 788.655(\mathrm{n}=8)$ & 0.265 \\
Control & $41.056 \pm 7.6894(\mathrm{n}=15)$ & $45.522 \pm 8.2318(\mathrm{n}=10)$ & 0.827 \\
\hline
\end{tabular}

Table 3. Mean PCT levels in patients of PTB and CAP with and without sepsis.

\begin{tabular}{cccc}
\hline Pulmonary Tuberculosis Group & $123.202 \pm 40.487(\mathrm{n}=23)$ & $377.912 \pm 157.3(\mathrm{n}=9)$ & 0.001 \\
Community-Acquired Pneumonia Group & $491.571 \pm 176.19(\mathrm{n}=14)$ & $1334.3 \pm 737.12(\mathrm{n}=9)$ & 0.000 \\
\hline
\end{tabular}

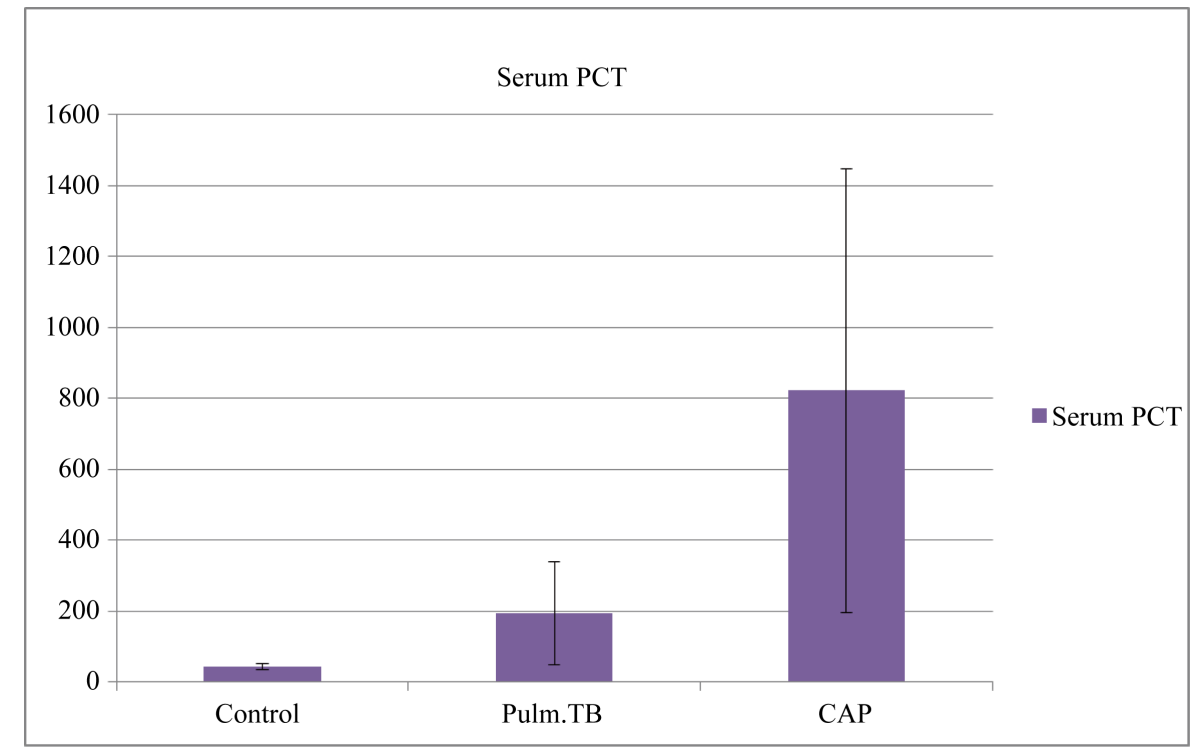

Figure 2. Mean PCT level (pg/ml) in study groups.

$<0.05$ as can be seen in Figure 4 .

Patients in CAP group were further categorized into those survived and expired. Mean PCT level were $548.778 \pm 232.2371 \mathrm{pg} / \mathrm{ml}$ and $1802.3 \pm 1802.3 \mathrm{pg} / \mathrm{ml}$ (mean $\pm \mathrm{SD}$ ) respectively, and there was significant difference with $\mathrm{P}$ value 0.004 as depicted in (Table 4, Figure 5).

\section{Discussion}

Pulmonary Tuberculosis (TB) is a major global health problem. Each year, there are around 9 million new cases of TB, and close to 2 million people die from the disease. India and China alone account for 35\% of all cases. Global scenario of pulmonary tuberculosis has markedly changed with the rise of HIV infection (Global TB Report 2011). Pulmonary tuberculosis is a granulomatous infectious disease of lung caused by Mycobacterium Tuberculosis. There are varied presentations of pulmonary tuberculosis, Secondary pulmonary tuberculosis being the most common. Sputum culture for Mycobacterium tuberculosis is the gold standard for diagnosis but sputum Z-N staining is most commonly used. Sputum Z-N staining is negative in 30\% - 50\% of patients (ATS 


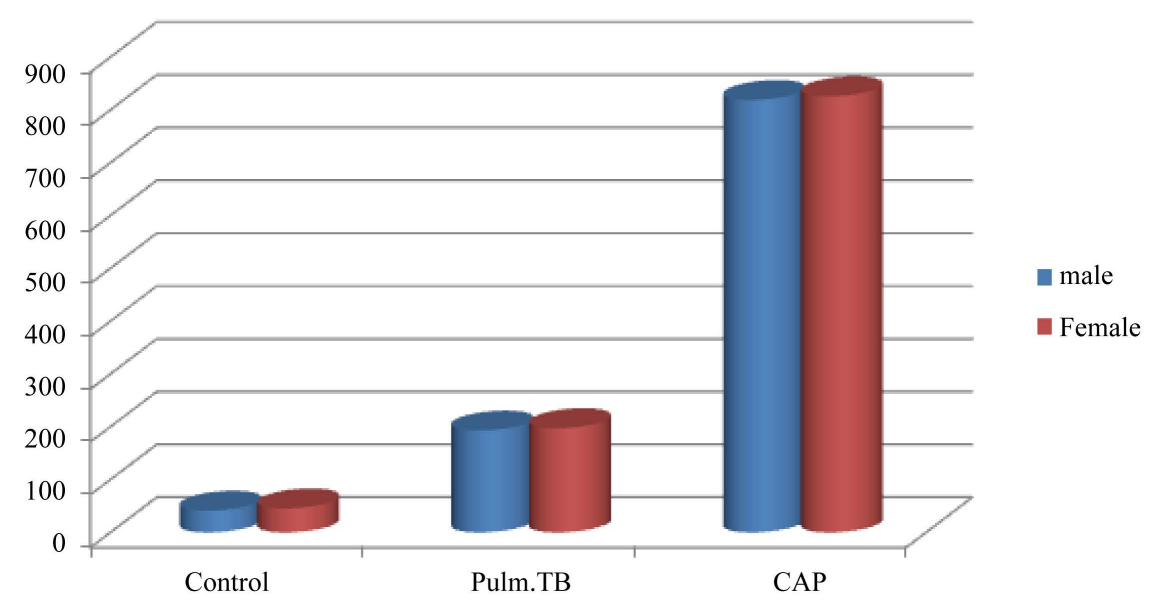

Figure 3. Mean PCT level (pg/ml) in male and female in different groups.

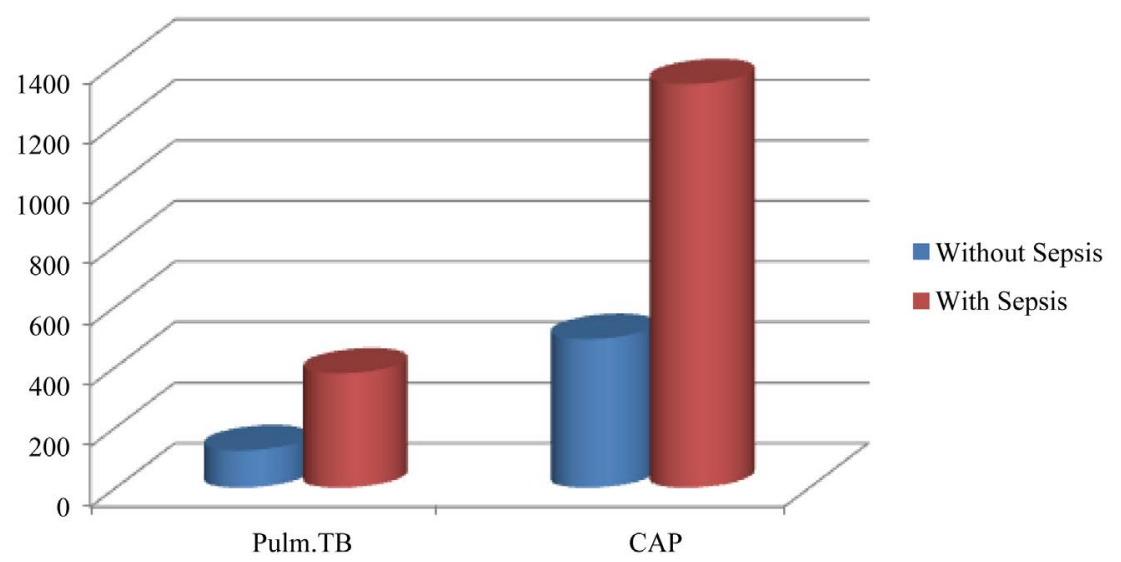

Figure 4. Mean PCT levels in patients of PTB and CAP.

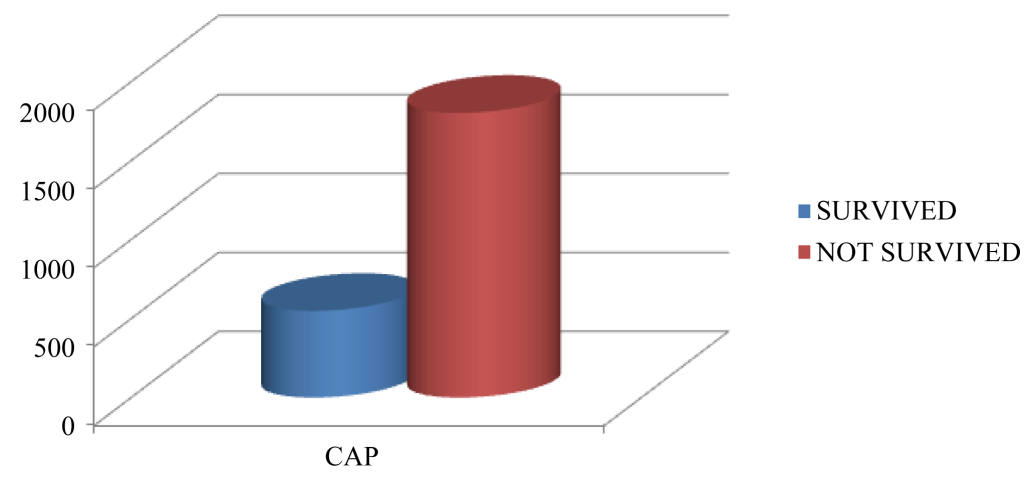

Figure 5. Mean PCT level in CAP patients in survived and expired patients.

Table 4. PCT Levels in survived and expired group of CAP.

\begin{tabular}{cccc}
\hline Group & Survived & Expired & P value \\
\hline Community-Acquired Pneumonia Group & $548.778 \pm 232.2371(\mathrm{n}=18)$ & $1802.3 \pm 1802.3(\mathrm{n}=5)$ & 0.004 \\
\hline
\end{tabular}

and CDC 2003). These sputum negative patients can be differentiated from community-acquired pneumonia by other modality of investigation (sputum culture for Mycobacterium, Bronchial lavage or Histopathological examination) which are time taking, costly and require specialist. 
Community-acquired pneumonia is acute inflammation of lung parenchyma. Streptococcus pneumonae and Haemophilus influenzae are the most common cause of CAP [2]. Community-Acquired Pneumonia (CAP) is the third leading cause of death worldwide. Its incidence is on rise with increasing life expectancy. It mainly affects under five children and elderly $>65$ year age group. Hospitalization, complication and mortality are high in both the age group [3]. Almost 20\% of the hospitalized patients need intensive care admission [4] (Kaplan V et al., 2002) and $10 \%$ of CAP progress to non resolving pneumonia [1].

Procalcitonin is a peptide precursor of calcitonin. It is normally synthesized in parafollicular cells of thyroid gland but in systemic inflammation and sepsis it is also synthesized by parenchymal tissue specially, lung, liver, kidney and adrenal gland. It is not detectable in healthy individuals $(<10 \mathrm{pg} / \mathrm{ml})$. In various studies it has been found to be elevated in bacterial infection and sepsis. It has also been found to be elevated in Systemic Inflammatory Response Syndrome (SIRS) but to a lower degree than sepsis.

From the above literature we infer that there is need of alternate diagnostic investigation to differentiate sputum smear negative pulmonary tuberculosis from non-responding community-acquired pneumonia. Further, patients of CAP require severity assessment and prognosis assessment. PSI and CURB-65 severity assessment scores are somewhat limited by practicality and risk of miscalibration due to different patient populations and, therefore, have only moderate operational characteristics [5]. Therefore, there is need for new severity assessment parameter. With this background we have compared serum PCT level in pulmonary tuberculosis and CAP.

In community-acquired pneumonia mean serum procalcitonin level is significantly elevated as compared to pulmonary tuberculosis. Therefore, elevated procalcitonin level in presence of consolidation in chest x-ray may be useful in detection of bacterial pneumonia and can be used to differentiate between pulmonary tuberculosis and community acquired pneumonia. In our study mean serum PCT level was $194.834 \pm 145.2233 \mathrm{pg} / \mathrm{ml}$ in pulmonary tuberculosis group and mean serum PCT level in community-acquired pneumonia group was $821.317 \pm 6262.999 \mathrm{pg} / \mathrm{ml}$. Difference between two values was significant. Similar results were also reported by K. Nyamande and U.G. Lalloo. They also found a significant difference in serum PCT level in pulmonary tuberculosis $(4.164 \pm 1.197 \mathrm{ng} / \mathrm{ml})$ as compared to community-acquired pneumonia $(19.479 \pm 5.640 \mathrm{ng} / \mathrm{ml})$. The serum level of PCT measured by K. Nayamande and U.G. Lallo was much higher than our study. In "Procalcitonin-Guided Antibiotic Therapy and Hospitalization in Patients with Lower Respiratory Tract Infections" (ProHOSP) study, Schuetz P. et al. (2011) found that serum PCT of $>0.5 \mathrm{ng} / \mathrm{ml}$ is associated with severe sepsis and high mortality rate [6]. Ugajin M et al (2011) studied PCT level in pulmonary tuberculosis patients and Pneumonia patients he also reported significant difference in PCT level in the two group (mean PCT in PTB group was $210 \pm 490 \mathrm{pg} / \mathrm{ml}$ and in Pneumonia group was $4100 \pm 8680 \mathrm{pg} / \mathrm{ml}$ ) [7]. In a study by G.K. Schleicher et al. on Pneumococcal pneumonia and pulmonary tuberculosis in HIV positive patients mean PCT level was 1030 $\mathrm{pg} / \mathrm{ml}$ and $19050 \mathrm{pg} / \mathrm{ml}$ in the two group, respectively, with P value of $<0.0005$ [8].

\section{Conclusions}

The present study entitled "Comparison of Serum Procalcitonin Level in Pulmonary Tuberculosis and Community-Acquired Pneumonia” is a prospective study. The study was conducted in Department of Tuberculosis and Respiratory Diseases and Department of Biochemistry, Jawaharlal Nehru Medical College, Aligarh during 2011-2013, on 80 subjects (32 Pulmonary Tuberculosis, 23 CAP and 25 Control). The aim of study was to compare serum procalcitonin level in pulmonary tuberculosis and CAP and its role as prognostic marker in CAP.

- Serum procalcitonin levels were found to be significantly elevated in patients of community-acquired Pneumonia as compared to patients of pulmonary tuberculosis.

In presence of consolidation in chest x-ray, increased level of serum procalcitonin may be used to differentiate pulmonary tuberculosis from community-acquired pneumonia. High level of serum procalcitonin is associated with high mortality rate in community-acquired pneumonia patients. This study merits further evaluation.

\section{References}

[1] Menendez, R., Perpina, M. and Torres, A. (2003) Evaluation of Non-Resolving and Progressive Pneumonia. Seminars in Respiratory Infections, 18, 103-111.

[2] Lim, W.S., Macfarlane, J.T., Boswell, T.C., et al. (2001) Study of Community-Acquired Pneumonia Aetiology (SCAPA) in Adults Admitted to Hospital: Implications for Management Guidelines. Thorax, 56, 296-301. 
http://dx.doi.org/10.1136/thorax.56.4.296

[3] Lieberman, D., Lieberman, D., Schlaeffer, F. and Porath, A. (1997) Community-Acquired Pneumonia in Old Age: A Prospective Study of 91 Patients Admitted from Home. Age Ageing, 26, 69-75. http://dx.doi.org/10.1093/ageing/26.2.69

[4] Kaplan, V., Angus, D.C., Griffin, M.F., Clermont, G., Scott, W.R. and Linde-Zwirble, W.T. (2002) Hospitalized Community-Acquired Pneumonia in the Elderly: Age- and Sex-Related Patterns of Care and Outcome in the United States. American Journal of Respiratory and Critical Care Medicine, 165, 766-772. http://dx.doi.org/10.1164/ajrccm.165.6.2103038

[5] Schuetz, P., Koller, M., Christ-Crain, M., et al. (2008) Predicting Mortality with Pneumonia Severity Scores: Importance of Model Recalibration to Local Settings. Epidemiology and Infection, 136, 1628-1637. http://dx.doi.org/10.1017/S0950268808000435

[6] Schuetz, P., Suter-Widmer, I., Chaudri, A., Christ-Crain, M., Zimmerli, W. and Mueller, B. for the Procalcitonin-Guided Antibiotic Therapy and Hospitalisation in Patients with Lower Respiratory Tract Infections (ProHOSP) Study Group (2011) Prognostic Value of Procalcitonin in Community-Acquired Pneumonia. European Respiratory Journal, 37, 384-392. http://dx.doi.org/10.1183/09031936.00035610

[7] Ugajin, M., Miwa, S., Shirai, M., Ohba, H., Eifuku, T., Nakamura, H., Suda, T., Hayakawa, H. and Chida, K. (2011) Usefulness of Serum Procalcitonin Levels in Pulmonary Tuberculosis. European Respiratory Journal, 37, 371-375. http://dx.doi.org/10.1183/09031936.00011910

[8] Schleicher, G.K., Herbert, V., Brink, A., Martin, S., Maraj, R., Galpin, J.S. and Feldman, C. (2005) Procalcitonin and C-Reactive Protein Levels in HIV-Positive Subjects with Tuberculosis and Pneumonia. European Respiratory Journal, 25, 688-692. http://dx.doi.org/10.1183/09031936.05.00067604 
Scientific Research Publishing (SCIRP) is one of the largest Open Access journal publishers. It is currently publishing more than 200 open access, online, peer-reviewed journals covering a wide range of academic disciplines. SCIRP serves the worldwide academic communities and contributes to the progress and application of science with its publication.

Other selected journals from SCIRP are listed as below. Submit your manuscript to us via either submit@scirp.org or Online Submission Portal.
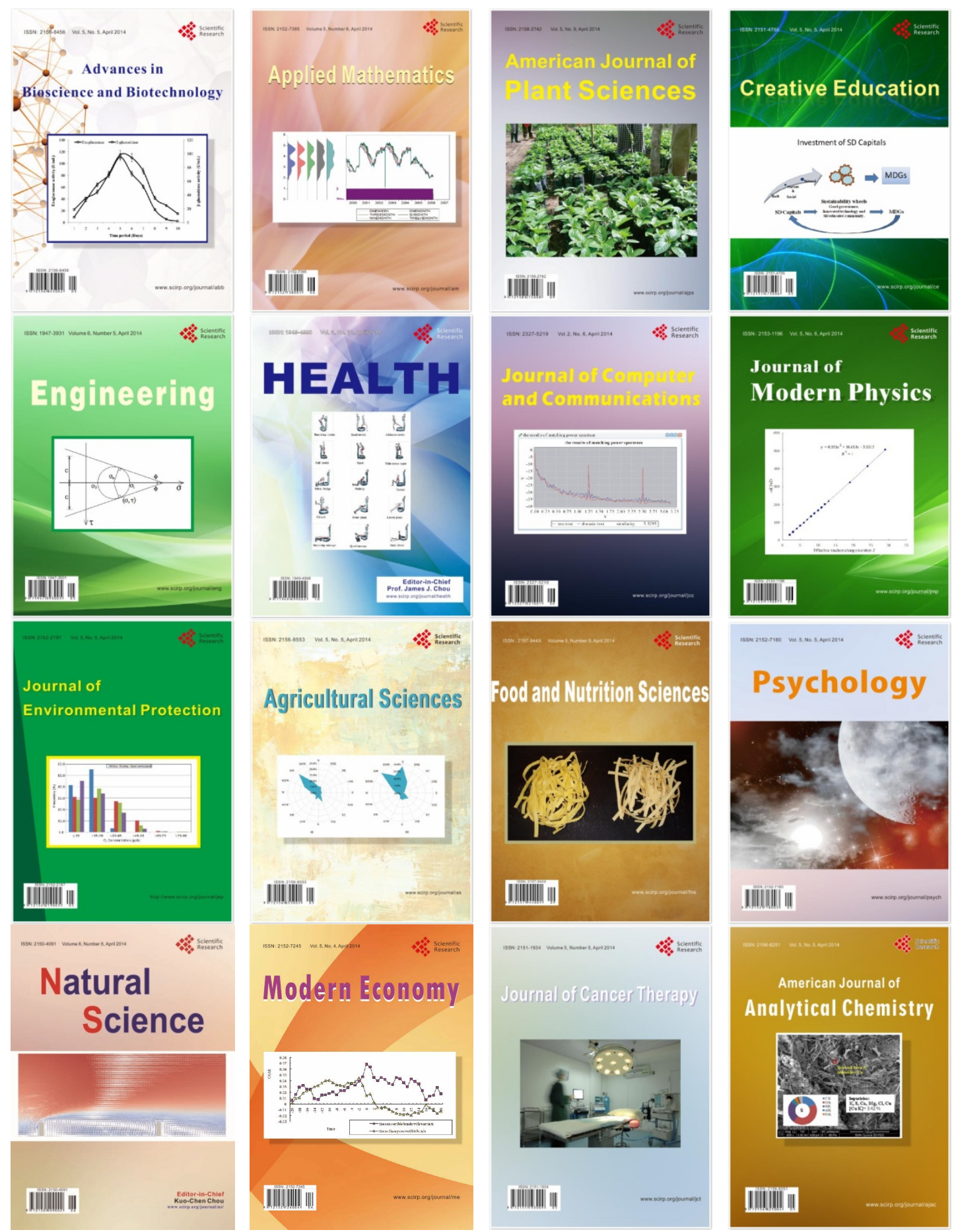